\title{
The concomitant use of venlafaxine and orphenadrine citrate plus paracetamol can produce acute cutaneous reaction: a case report
} study

\author{
G Theleritis ${ }^{1}$, George Papadimitriou*1, C Papageorgiou ${ }^{1}$, \\ Dimitrios Kalogeromitros ${ }^{2}$ and A Rabavilas ${ }^{1}$
}

\author{
Address: ${ }^{1}$ Department of Psychiatry, Athens University Medical School, Eginition Hospital, Greece and ${ }^{2}$ Department of Dermatology, Athens \\ University Medical School, Eginition Hospital, Greece \\ * Corresponding author
}

\author{
from International Society on Brain and Behaviour: 2nd International Congress on Brain and Behaviour \\ Thessaloniki, Greece. 17-20 November 2005 \\ Published: 28 February 2006 \\ Annals of General Psychiatry 2006, 5(Suppl I):SI35 doi:I0.II86/I744-859X-5-SI-SI 35
}

\section{Background}

Coadministration of various drugs together with antidepressants can induce different side-effects in depressed patients. The authors report the case of a middle-aged woman, suffering from recurrent unipolar mood disorder, who developed an acute cutaneous reaction after the concomitant use of venlafaxine $225 \mathrm{mg} /$ day and a combination product of orphenadrine citrate $105 \mathrm{mg} /$ day and paracetamol $1350 \mathrm{mg} /$ day.

\section{Materials and Methods}

To address whether the occurrence of this cutaneous reaction was the result of a possible allergic reaction or a drugdrug interaction.

In an attempt to identify the origin of this adverse effect, skin prick tests were performed in the patient with orphenadrine citrate and paracetamol in multiple dilutions. Five non-depressed patients, without a medical history of atopy, to whom it was recently prescribed orphenadrine citrate and paracetamol, were evaluated and were used as controls.

\section{Results}

Skin tests to orphenadrine citrate and paracetamol were negative both for the patient under consideration, as well as for the members of the control group. In addition, none of the individuals studied developed any delayed skin test reactions.

\section{Discussion}

According to our findings, the possibility of an allergic reaction due to the concomitant use of venlafaxine and this combination product of orphenadrine citrate and paracetamol cannot be supported, since skin prick tests were negative. Thus, it is suggested that this cutaneous reaction is probably due to a drug-drug interaction between venlafaxine and this combination product. 